\title{
Battery Charging Optimization of Solar Energy based Telecom Sites in India
}

\author{
Dheeraj Kumar Dhaked \\ Department of Electrical Engineering \\ Rajasthan Technical University \\ Kota, Rajasthan, India \\ ddhakar9@gmail.com
}

\author{
Yatindra Gopal \\ Department of Electrical Engineering \\ Rajasthan Technical University \\ Kota, Rajasthan, India \\ ygopal.phd@rtu.ac.in
}

\author{
Dinesh Birla \\ Department of Electrical Engineering \\ Rajasthan Technical University \\ Kota, Rajasthan, India \\ birlartu2@gmail.com
}

\begin{abstract}
Telecom sites get the power normally from the grid. At the occurrence of power outages power need to be supplied for telecom sites. The battery bank is a good option for telecom sites to fulfil power demand. This paper discusses a smooth battery bank charging and discharging system with solar power as the input supply source. The system requires a large capital investment, but it provides uninterrupted emergency power when needed. Maintaining battery banks is essential for getting optimum performance. This paper also discusses the power requirements for telecom sites backup and various parameter impacts on battery life. Methods are derived to optimize charging management of batteries in order to get maximum lifespan in addition to better battery performance throughout its useful life.
\end{abstract}

Keywords-telecom site; battery bank; charging-discharging; maximum power point tracking (MPPT)

\section{INTRODUCTION}

The telecom industry of India is growing at a very fast pace. Telecom sites require uninterrupted power supply [1]. The main problem of the telecom sites is that rural areas have only 6 to 10 hours of power supply from the grid. To fulfil this demand, two ways are possible, either by grid or by some other renewable source, i.e. solar, biomass, wind, etc. [2]. Also, there are other issues which make this solution worthy:

- The dismal state of rural electrification

- Non-availability of grid power in rural areas

- The grid might be away from the site

- Poor grid power quality

- Unreliable \& erratic power behavior

The use of renewable power sources also reduces environmental deteriorating agents, as carbon emission for power generation, thus rural sites will get reliable power for operation. Solar energy is one of the best options as it is totally free of cost and can be harvested easily with available means like solar plates, inverters, and converters. The power harvested from the sunlight during the day can also be used during the night hours if stored in battery banks [3-4]. The power demand for a single telecom site ranges from 1 to $4 \mathrm{~kW}$ for $24 \times 7$ hour operation. For back-up, it requires a 15-20kVA diesel generator set (DG) which has $41 / \mathrm{h}$ diesel consumption. The running time of the DG set is 6-10 hours per day in grid-connected areas but for about 14-16 hours in rural areas the grid is not available. The burning of diesel causes the emission of greenhouse gases (GHG) (carbon dioxide, methane, nitrous oxide etc.). Solar energy can fulfil telecom sites' load in day-time, while during night hours charged batteries can supply the system. The battery banks set-up will be placed at the telecom site and as an economical solution for back-up [5]. Lead-acid battery model for simulation with solar system via a DC-DC converter with battery set-up was used in [6-7].

In this paper, particle swarm optimization (PSO) algorithm is used for battery charging. This paper also describes an equivalent circuit model for battery and solar cell, and a battery model is made to match the model from the datasheet of the manufacturer. The performance of the battery cell, while being charged by solar array cell is also simulated. Multiple modes of operation and scenarios which cause early battery failure are described in [8-11] and are taken into consideration while proceeding to develop the most suitable battery charging method.

\section{A. Study Objectives}

- To introduce the reader to current energy-efficient technologies which are environment supportive.

- To study the solar fed battery bank system with model implementation in Matlab.

- To study the behavior of the model for battery charging and discharging and analyze its characteristics.

\section{B. Problem Statement}

- Energy consumption from telecom network is an increasing contributor to GHG emission.

- Limiting carbon dioxide emissions will be more difficult for most of the countries where electric generation comes primarily from coal such as India.

- The carbon emission footprint of the telecom sector has risen significantly and will rise despite the development of energy-efficient technologies. 


\section{Methodology OF BATTERY CHARGING OPTIMIZATION}

As the scope of this manuscript is to develop modified charging algorithms for batteries, one has to reach to the exact traditional charging profile before using the suggested algorithms, according to battery chemistries and strict Do's and Don'ts which must be kept in the algorithms. While varying parameters of batteries and changing operating conditions, critical parameters, like thermal dissipation which causes gassing and ageing of batteries, have to be observed and improved [6]. Input varying conditions, like solar charging current, have to be simulated in most real-time scenarios to see the impact and sizing of solar panels to be optimized [4]. In most cases, the power input from solar panels is insufficient to keep the batteries full charged, especially during sunless days. In such conditions, the battery remains in partial state of charge (PSOC) and deep cycling. Solar systems are installed in conditions where battery temperatures remain usually high [78]. Normal lead-acid batteries fail in such conditions due to sulphating, corrosion, and active material shedding. Water topup in remote sites is difficult also. Hence, the best option is gel batteries with VRLA technology. For solar applications, charging hours are limited by sunlight availability. Boost charge can be given every day since charging current and ambient temperature during the evening are already decreased to a certain level [9-11]. It would not lead to any heat generation or any other negative effect, but will help keep sulphation away because higher voltage kills sulphation and hence plates remain fresh and battery cycle life increases. In order to achieve the implementation of the above, a nominal charging algorithm has been modified to give everyday equalization charge keeping close monitoring of cell temperature avoiding any ill effect of heat to cycle life [12]. By removing sulphation, lead plates remain fresh and hence battery lasts longer as lead plate sulphation is a significant part in determining the battery life [13-15].

\section{MPPT AND BATTERY CHARGING OPTIMIZATION}

Optimization is the mechanism which finds the maximum or minimum value of a function or process. It is used in fields such as physics, chemistry, economics, and engineering where the goal is to maximize efficiency, production, or some other measure. To gain the maximum power output, an MPPT technique is used in the form of an electronic system that operates with the PV system. The maximal power point (MPP) doesn't reach an exact end or point but it gets moving around the PV curve that depends on light intensity of irradiation and the temperature. The PSO MPPT is used and the flowchart of this algorithm is given in Figure 1. The PSO algorithm finds the best possible resolution of swarm particles through the particle's progress in the investigation space with its optimized velocity and position. It finds the optimum solution by obtaining the minimum value of the given objective function [16]. The outline of the PSO algorithm is presented below.

Step I: Initialize the particles with random numbers having a consistent distribution: $Y=$ Vrand (plowerlim, pupperlim). Assign this position to the best known position array: $r=Y$. Initialize particle velocity: $V=Y$. If the number of particles is Nump then, $Y$ is the size of the array of particle positions.
Similarly, $r$ is an array of pbest positions, and $V$ is a Nump-size array of particle velocities.

Step II: Calculate the fitness function: $E y=F(Y), E r=F(r)$, and $e g=f($ gbest $)$, where $E y$ and $E r$ are the fitness evaluation arrays for $y$ and $r$, respectively, and $e g$ is the function evaluation at gbest.

Step III: Update pbest value for each particle of the population: if $\operatorname{Ey}(i)<\operatorname{Er}(i)$ then $r(i)=Y(i)$, where $i=1,2, \ldots$ Nump.

Step IV: Update gbest value for the entire population:

if $\operatorname{Er}(i)<e g$ then $g b e s t=\mathrm{r}(\mathrm{i})$.

Step V: Update the velocity and position of the particles:

$$
\begin{gathered}
V(i+1)=w V(i)+C_{1} \operatorname{rrand}(0,1)(r(i)-Y(i))+C_{2} \operatorname{rrand}(0,1) \\
(\text { gbest }-Y(i)), Y(i+1)=Y(i)+V(i+1)
\end{gathered}
$$

where $w$ is the initial weight, $C_{1}$ is the cognitive parameter, and $C_{2}$ is the social parameter.

Step VI: Exit criterion is generally a fitness threshold or a highest number of iterations. If the criterion is met, then exit or else, go to step II.

The PSO works by simultaneously maintaining several candidate solutions in the search space [6]. During each iteration, each candidate solution is evaluated by the objective function to be optimized, determining the fitness of that solution. Each candidate solution can be thought of as a particle "flying" through the fitness landscape finding the maximum or minimum of the objective function.

\section{MODELING AND SIMULATION}

The equivalent circuit model of a lead-acid battery is a voltage source connecting with the internal resistance. State of Charge (SOC), temperature and other elements of the battery parameters of circuit are related by the relationship between the resistance and voltage of capacitor. Each cell of the lead-acid battery produces $2 \mathrm{~V}$. Total terminal voltage will vary according to the working conditions. The concentration of the acid will change during charge and discharge [10]. The experiment has the following steps.

- Study of the battery used in the experiment and research data from various sources.

- Design of the battery circuit and the block diagram of a mathematical model using Simulink.

- Simulations at different temperatures from 25 to $60^{\circ} \mathrm{C}$ have to be conducted and recording for current and voltage graph has to be done.

In this section, modeling of lead acid battery is done using the Simscape language in order to implement nonlinear equations of the component of equivalent circuit as shown in Figure 2. In this way, defining physical equations and the connection between model components described. The study in [13] is referred for defining equations and their validation. 


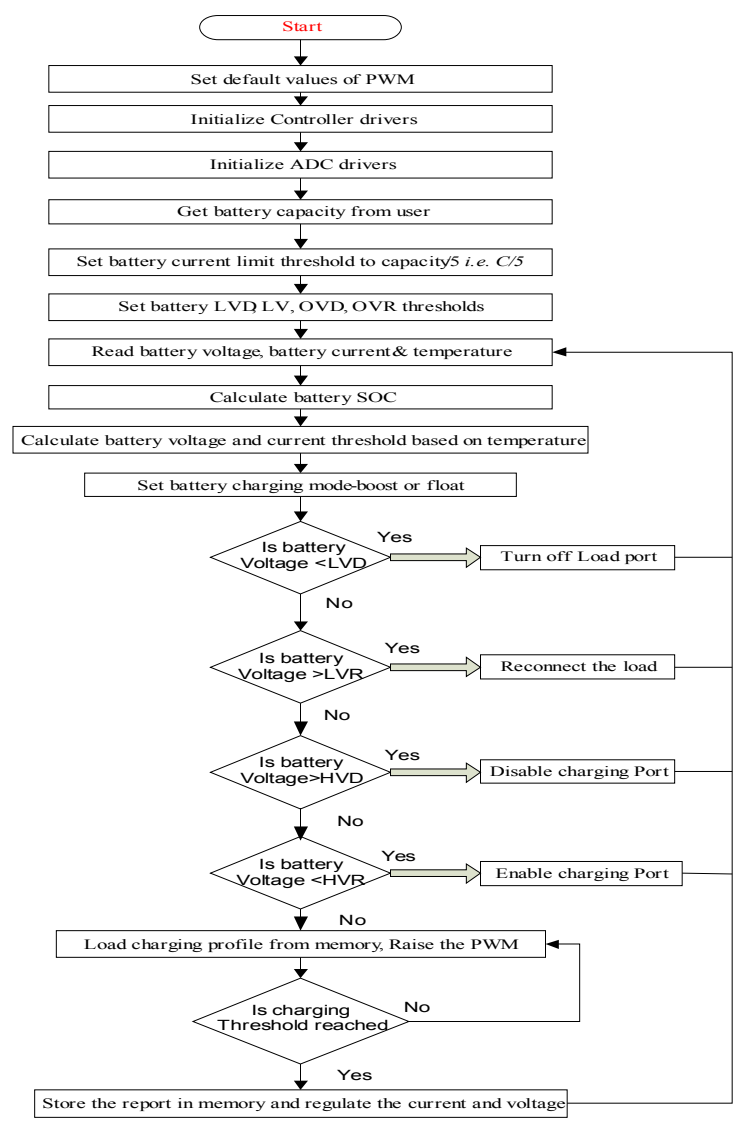

Initially, the battery is discharged at a load current of $10 \mathrm{~A}$ in the simulation and then further recharged at a current of $10 \mathrm{~A}$ to return to the initial state of charge. A simple thermal model is used to model battery temperature. It is considered that cooling is done primarily via convection method and that heating is mainly from the internal battery resistance R2. A standard $12 \mathrm{~V}$ lead-acid battery is modelled by connecting six $2 \mathrm{~V}$ battery cell blocks in series, or for telecom applications of $48 \mathrm{~V}$, more $2 \mathrm{~V}$ cells should be used in series [10-11]. Once the battery model is developed, then to simulate the application, a simulation profile is created where both charging and discharging parameters using controlled current sources and controlled load sources are programmed to simulate the actual conditions of solar panel and grid-based battery charging [14$15]$.
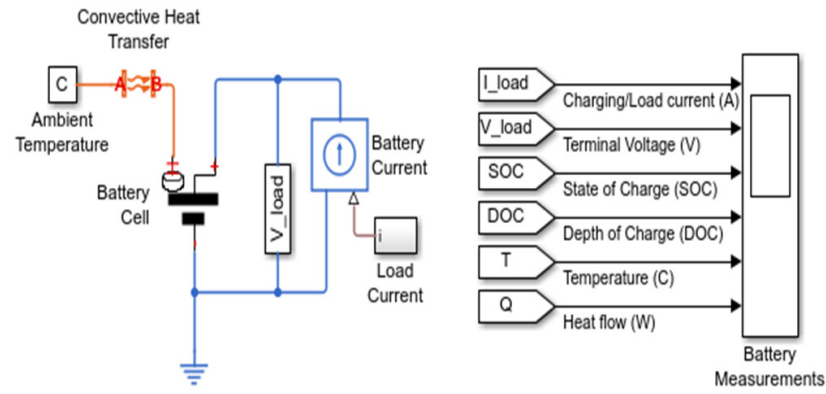

Fig. 2. Battery simscape model

Fig. 1. PSO algorithm flowchart for digital control loop for battery charging

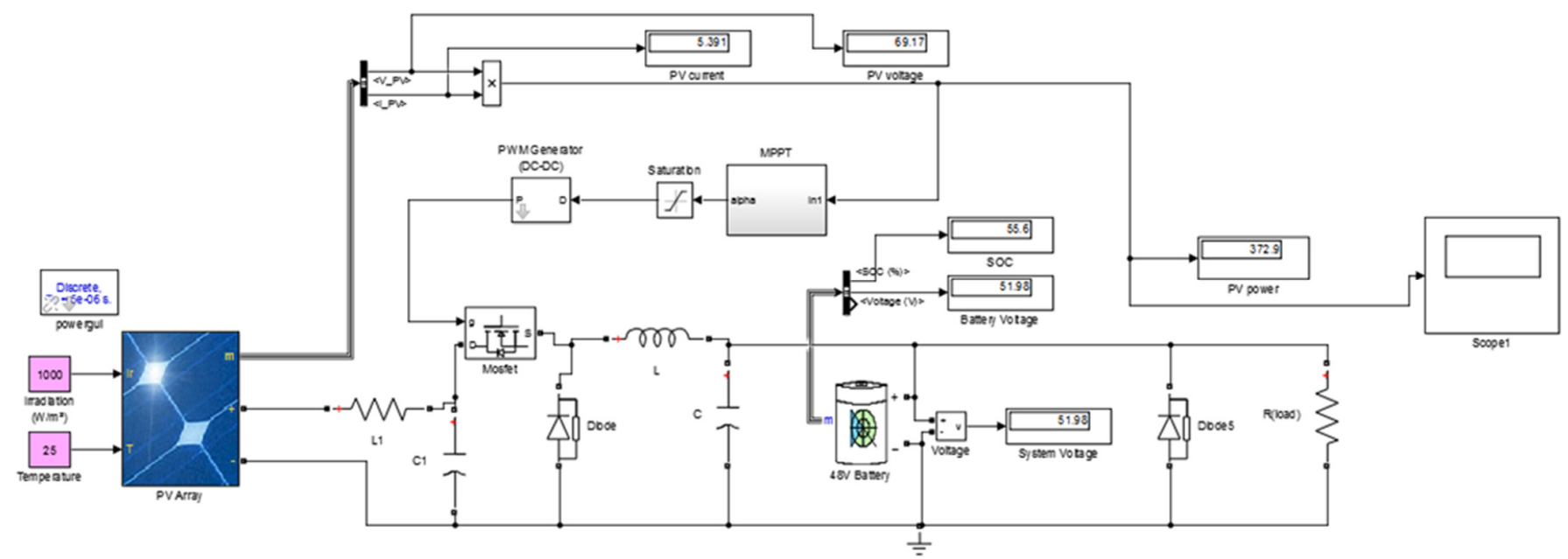

Fig. 3. Simulink model for lead acid battery capacity $=100 \mathrm{Ah}$, battery nominal voltage $=52 \mathrm{~V}$, response time $=30 \mathrm{~s}$, initial $\mathrm{SOC}=100 \%$

\section{DESCRIPTION OF SIMULATION CIRCUIT}

The simulation circuit components of Figure 3 are:

- Energy source: A solar panel providing $35 \mathrm{~V}$ voltage and $10 \mathrm{~A}$ current.

- Battery: A battery model with $48 \mathrm{~V}$ nominal voltage and respective internal resistance as per battery model.
- Load: One controlled resistance is used in the simulation circuit which represents the telecom load for which the entire system has to be made.

- Voltage conversion module: A DC-DC boost converter to change the solar panel voltage to battery charging voltage in a controlled manner. 
- Monitoring modules: The necessary voltage and current measurement devices are used in the simulation circuit.

- Simulation: The DC-DC boost converter is used to boost the voltage to battery voltage and the whole circuit acts as a current limited source to charge the battery up to the desired voltage using the current source. Using the PWM controller in the boost converter, the desired charging current can be set when charging the battery in bulk charging mode. It depends on the profile which is based on the charging and discharging time status of the battery voltage, current, solar module voltage and power output w.r.t. sunlight.

Once the battery voltage reaches full charge, it can be controlled to enter in constant voltage-based charging. In this case, the battery voltage reaches a constant value of $56 \mathrm{~V}$ and the battery current starts decreasing slowly with time. With different charging current limits the battery voltage and SOC can be plotted with charging current. With different charging voltage settings in constant charging voltage mode, the charging performance can be optimized [17-19]. With this practical simulation model, any permutation and combination of charging voltage versus charging current and battery SOC can be developed and tested. The PSO algorithm is loaded in the PWM controller in the simulation model. Different charging and discharging curves are below simulating different battery sizes, charging voltages and charging current to confirm the system's functionality.

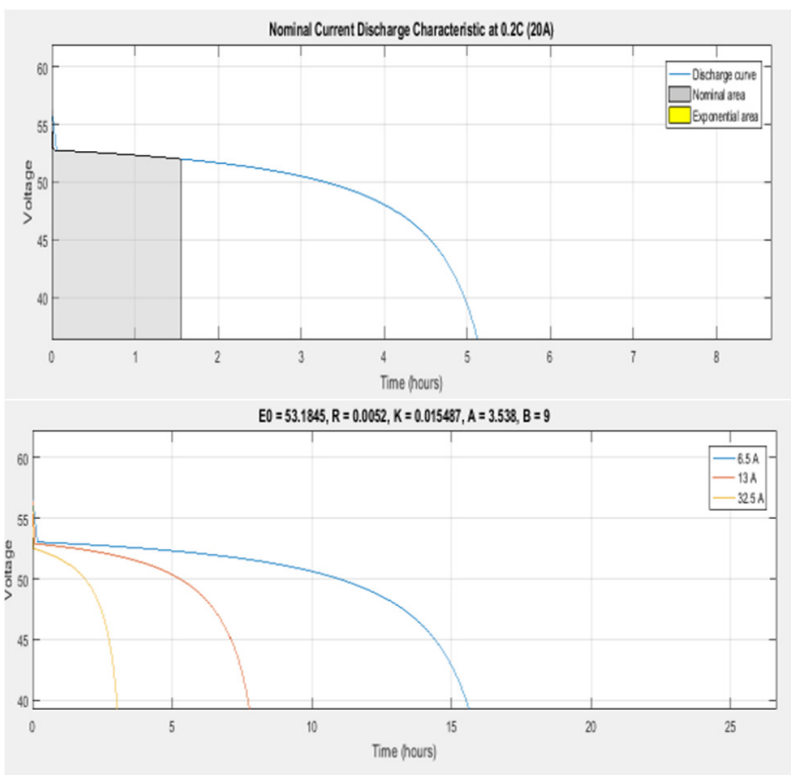

Fig. 4. Discharge characteristics of lead-acid battery: Capacity=100Ah, nominal voltage $=52 \mathrm{~V}$, response time $=30 \mathrm{~s}$, initial $\mathrm{SOC}=100 \%$

The discharge characteristic of lead-acid battery for $100 \mathrm{Ah}$ capacity, $52 \mathrm{~V}$ battery voltage and $100 \%$ SOC is shown in Figure 4 . The discharge characteristic of lead-acid battery for $50 \mathrm{Ah}$ capacity, $13.5 \mathrm{~V}$ battery voltage, and $90 \% \mathrm{SOC}$, is shown in Figure 5. The discharge characteristic of lead-acid battery for capacity of $100 \mathrm{Ah}, 26.5 \mathrm{~V}$ battery voltage and $80 \%$ SOC is shown in Figure 6.
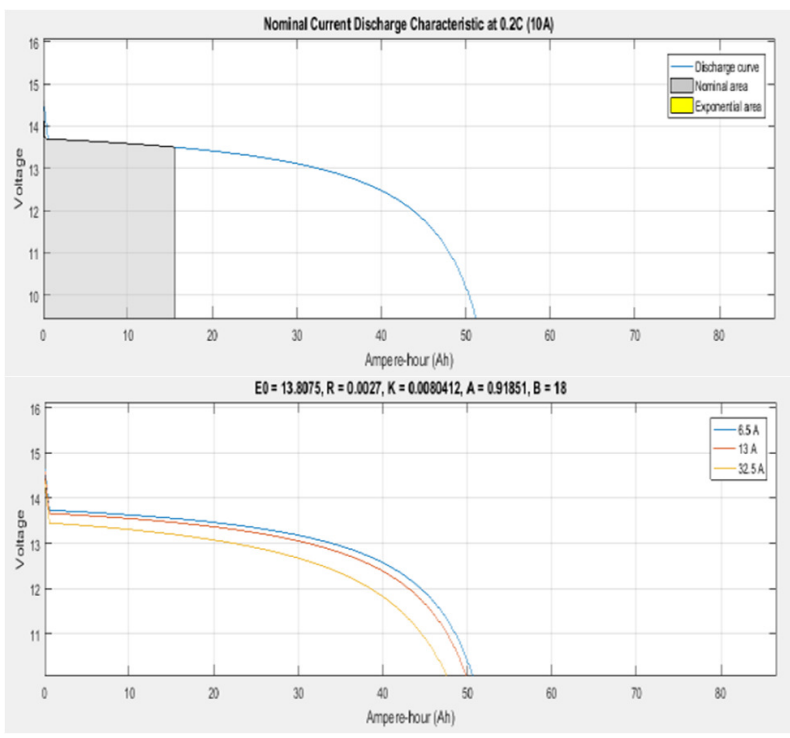

Fig. 5. Discharge characteristics of lead-acid battery: Nominal voltage $=13.5 \mathrm{~V}$, rated capacity $=50 \mathrm{Ah}$, initial $\mathrm{SOC}=90 \%$, battery response time $=30 \mathrm{~s}$

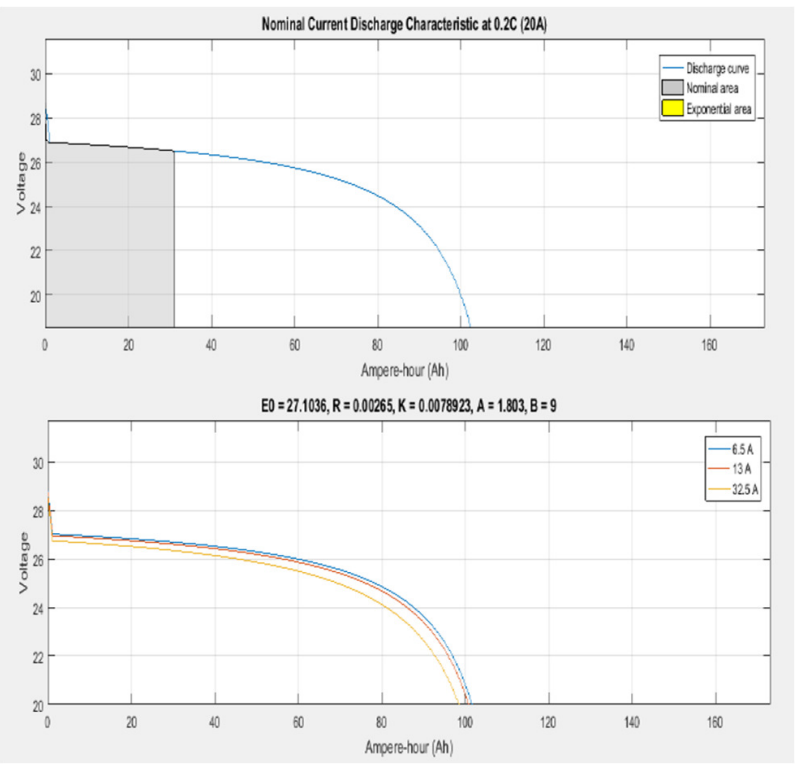

Fig. 6. Discharge characteristics of lead-acid battery: Initial $\mathrm{SOC}=80 \%$, capacity $=100 \mathrm{Ah}$, nominal voltage $=26.5 \mathrm{~V}$, response time $=20 \mathrm{~s}$

\section{SimULATION RESULTS}

The results of the above mentioned simulations are:

- Battery temperature rise is controlled by maximum battery charging current. Current control is done through measuring the battery internal temperature by mounting the temperature sensor on the negative terminal of the battery.

- When battery temperature control is done, the cycle life of batteries can be determined directly by the exclusive data provided by the manufacturer. This is usually at $25^{\circ} \mathrm{C}$ as a function of depth of discharge in the cycle and the number of cycles. 
- The charging profile is matched to the ideal charging profile given by the battery manufacturer. Gassing can be controlled in simulations and the desired battery performance will be achievable when the system's operational needs are very close to the ideal conditions.

- When the battery is charged and discharged using properly rated charging power, daily SOC are at the higher sides of the SOC scale. Minimum battery SOC after overnight discharge is $80 \%$ and $100 \%$ during charging time at around 3 PM. This results in highest cycle life as given in the Depth of Discharge (DOD) vs cycle life chart provided by the battery manufacturer.

- When the battery capacity selected for required load is as mentioned above, batteries are usually sized as per standard discharge current and capacity. Usually, all batteries are rated as $\mathrm{C} / 20$ or $\mathrm{C} / 10$.

- In telecom conditions, more than 25 hours back-up is needed for the batteries to operate to $\mathrm{C} / 40$ or greater (up to $\mathrm{C} / 100)$ rating. This provides a very high cycle life but it requires increasing the low voltage disconnect threshold level depending on discharging current rating.

\section{PRACTICAL RESULTS}

After applying the PSO algorithm, it has been observed that the daily SOC battery level stayed from $80 \%$ to $100 \%$ and the voltage level ranged between $65 \%$ and $85 \%$, hence the cycle life is certainly expected to increase. Figure 7 shows the SOC variation before applying PSO MPPT algorithm. The SOC stayed between $65 \%$ and $80 \%$ throughout the week.

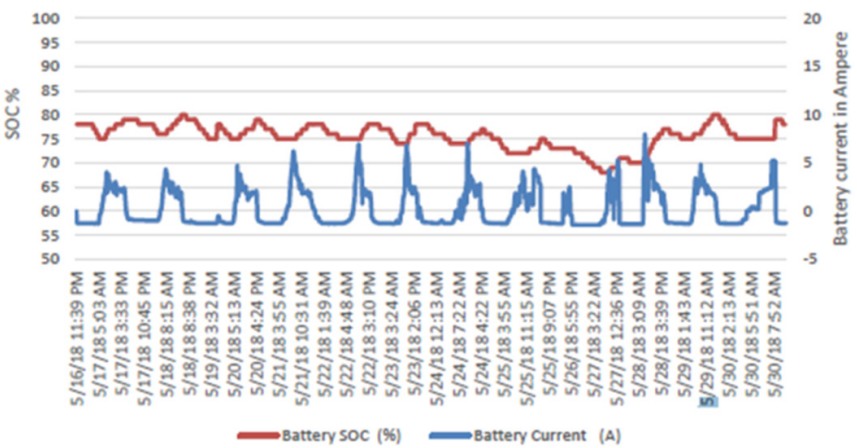

Fig. 7. SOC variation before applying PSO algorithm. SOC stays between $65 \%$ and $80 \%$

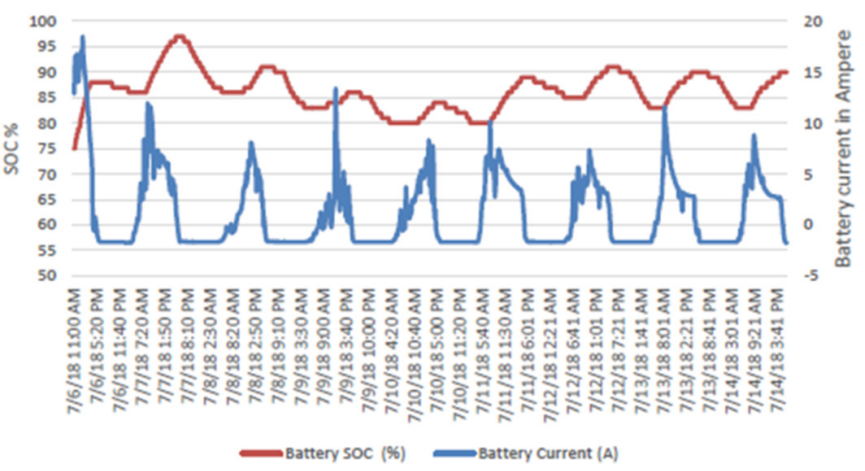

Fig. 8. SOC variations after applying PSO. SOC stays above $80 \%$
Battery's life cycle was around 4000 cycles, as shown in Figure 9. Figure 8 shows the SOC variation after applying the PSO MPPT algorithm. It can be seen from Figure 9 that SOC stayed above $80 \%$ throughout the week. The battery cycle life became around 5500 cycles (Figure 9). It is observed that battery life increased by $30 \%$ with the suggested optimization.

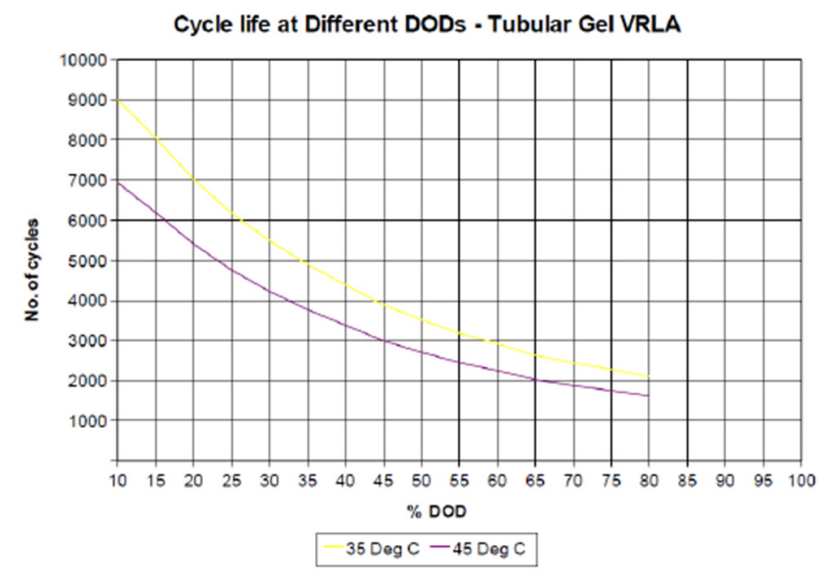

Fig. 9. Battery cycle life with respect to Depth of Discharge

\section{CONCLUSION}

In this paper, various parameters of charging battery and their respective impact on the battery cycle life were studied. While carefully considering all of them, an optimized charging method was driven which also takes proper sizing of battery bank and solar PV array into consideration. A lead-acid battery model was programmed in Matlab and its characteristics were studied. DC-DC boost converter-based current source and constant-voltage source equations were programmed in Matlab and their characteristics were studied. Advance battery charging method was driven and the performance impact on batteries was studied while operating with solar panels. Solar PV power system performance for $24 \times 7$ operating loads, such as telecom loads, is satisfactory when batteries perform for a long time and give better revenues to operators with less maintenance expenses. Optimum calculations of system sizing for solar PV array and battery banks capacity were also derived. With the help of the developed algorithm, 30\% more cycle life was achieved.

\section{REFERENCES}

[1] Intelligent Energy, The true cost of providing energy to telecom towers in India, available at: https://www.gsma.com/membership/wpcontent/uploads/2013/01/true-cost-providing-energy-telecom-towersindia.pdf, 2012

[2] R. Dabkeya, D. K. Dhaked, M. Lalwani, "An overview of gasifier and its application in Indian context", 3rd International Conference on Emerging Trends in Electrical, Communication and Information Technologies, Ananthapuramu, India, December 20-22, 2018

[3] N. Bashir, H. S. Sardar, M. Nasir, N. U. Hassan, H. A. Khan, "Lifetime maximization of lead-acid batteries in small scale UPS and distributed generation systems", 2017 IEEE Manchester PowerTech, Manchester, UK, November 5-8, 2017

[4] F. Chermat, M. Khemliche, A. Badoud, S. Latreche, "Techno-economic feasibility study of investigation of renewable energy system for rural electrification in southern Algeria", Engineering, Technology \& Applied Science Research, Vol. 8, No. 5, pp. 3421-3426, 2018 
[5] M. Garba, M. A. Tankari, G. Lefebvre, "Using of distributed energy resources for microgrid resilience achieving", IEEE 6th International Conference on Renewable Energy Research and Applications, San Diego, USA, December 5-8, 2017

[6] S. Chen, C. Kang, Z. Zhang, H. Zhu, "A method for SOC estimation for lead-acid battery based on multi-model adaptive extended Kalman filtering estimation", IECON 42nd Annual Conference of the IEEE Industrial Electronics Society, Florence, Italy, October 23-26, 2016

[7] K. Dhaked, S. Saini, P. Sharma, "Analysis of different converters for reduced total harmonic distortion and improved power factor", IEEE Fifth International Conference on Signal Processing and Integrated Networks, Noida, India, February 22-23,2018

[8] C. C. Freitas, M. B. Ketzer, M. R. A. Morais, A. M. N. Lima, "Lifetime estimation technique for lead-acid batteries", IECON 42nd Annual Conference of the IEEE Industrial Electronics Society, Florence, Italy, October 23-26, 2016

[9] J. F. A. Leao, L. V. Hartmann, M. B. R. Correa, A. M. N. Lima, "Leadacid battery modeling and state of charge monitoring", 2010 TwentyFifth Annual IEEE Applied Power Electronics Conference and Exposition, Palm Springs, USA, February 21-25, 2010

[10] Z. M. Salameh, M. A. Casacca, W. A. Lynch, "A mathematical model for lead-acid batteries", IEEE Transactions on Energy Conversion, Vol. 7, No. 1, pp. 93-98, 1992

[11] M. Y. Chen, M. F. Tsai, C. S. Tseng, S. Y. Yen, “A novel control strategy for multiphase battery chargers without Hall-effect current sensors", International Power Electronics Conference, Sapporo, Japan, June 21-24, 2010

[12] P. K. Manoharan, R. Mohan Kumar, K. Karthick, R. Sowmya, "SoC estimation and Mmnitoring of Li-ion cell using Kalman-rilter Algorithm", International Journal on Electrical Engineering and Informatics, Vol. 6, No. 4, pp. 418-427, 2018

[13] R. A. Jackey, "A simple, effective lead-acid battery modelling process for electrical system component selection", SAE World Congress \& Exhibition, April 2007

[14] J. Jana, H. Samanta, K. D. Bhattacharya, H. Saha, "Design and development of high efficiency five stage battery charge controller with improved MPPT performance for solar PV systems", International Journal of Renewable Energy Research, Vol. 8, No. 2, pp. 941-953, 2018

[15] A. Hassoune, M. Khafallah, A. Mesbahi, T. Bouragba, "Power management procedures of electric vehicle charging station based grid tied PV-battery system", International Journal of Renewable Energy Research, Vol. 8, No. 2, pp. 851-860, 2018

[16] M. M. Hoque, M. A. Hannan, A. Mohamed, "Charging and discharging model of lithium-ion battery for charge equalization control using particle swarm optimization algorithm", Journal of Renewable and Sustainable Energy, Vol. 8, No. 6, Article ID 065701, 2016

[17] M. S. Hossain Lipu, M. A. Hannan, A. Hussain, M. M. Hoque, P. J. Ker, M. H. M. Saad, A. Ayob, "A review of state of health and remaining useful life estimation methods for lithium-ion battery in electric vehicles: Challenges and recommendations", Journal of Cleaner Production, Vol. 205, No. 1, pp. 115-133, 2018

[18] U. B. Tayab, M. A. Al Humayun, "Modeling and analysis of a cascaded battery-boost multilevel inverter using different switching angle arrangement techniques", Engineering, Technology \& Applied Science Research, Vol. 7, No. 2, pp. 1450-1454, 2017

[19] Y. Gopal, K. Kumar, D. Birla, M. Lalwani, "Banes and boons of perturb \& observe, incremental conductance and modified Regula Falsi methods for sustainable PV energy generation", Journal of Power Technologies, Vol. 97 , No. 1, pp. 35-43, 2017 